\title{
Energy scenario choices: insights from a retrospective review of UK energy futures
}

\section{Authors:}

Evelina Trutnevyte ${ }^{1,2 *}$, Will McDowall1, Julia Tomei ${ }^{1}$, Ilkka Keppo ${ }^{1}$

* Corresponding author, trutnevyte@sccer-soe.ethz.ch, phone +41446338705

${ }^{1}$ University College London, UCL Energy Institute, 14 Upper Woburn Place, London WC1H 0NN, United Kingdom

2 ETH Zurich, Department of Environmental Systems Science (D-USYS), USYS Transdisciplinarity Laboratory, Universitätstrasse 22, 8092 Zurich, Switzerland

\begin{abstract}
Since the 1980s, there has been a shift in energy research. It has shifted from approaches that forecast or project the future to approaches which make more tentative claims and which explore several plausible scenarios. Due to multiple uncertainties in energy systems, there is an infinite amount of plausible scenarios that could be constructed and scenario developers therefore choose smaller, more tangible sets of scenarios to analyse. Yet, it is often unclear how and why this scenario choice is made and how such choices might be improved. This paper presents a retrospective analysis of twelve UK energy scenarios developed between 1978 and 2002. It investigates how specific scenarios were chosen and whether these choices captured the actual UK energy system transition. It finds that scenario choice reflected contemporary debates, leading to a focus on certain issues and limiting the insights gleaned from these exercises. The paper argues for multiorganisation and multi-method approaches to the development of energy scenarios to
\end{abstract}


capture the wide range of insights on offer. Rather than focus on uncertainty in model parameters, greater reflection on structural uncertainties, such as shifts in energy governance, is also required.

\section{Keywords}

Energy scenarios, scenario choice, retrospective analysis, historical analysis, modelling

\section{Introduction}

The past few decades have witnessed a rapid increase in the development of quantitative energy scenarios for research and decision-making. Especially since the 1980s, there has been a shift away from approaches that forecast or project the future to approaches that explore several plausible scenarios. Figure 1 illustrates this shift in the wider literature: Google NGram Viewer [1,2] is used to depict the relative frequency with which the case-insensitive terms "forecast," "projection" and "scenario" have appeared in digitised English books between 1900 and 2000. Since this shift from forecasting and projecting to an exploration of energy futures through scenarios, most studies now explore at least two alternative scenarios, c.f. [3-6]. Multiple complexities and uncertainties in energy systems result in an infinite number of plausible scenarios that could be imagined. However, limited cognitive capacity means that the "magical number of seven plus or minus two" is the number of objects that an average person can have and retrieve from working memory [7]. Thus, even experts may not be able to simultaneously remember and manipulate many more scenarios than this. The need to choose smaller sets of scenarios for interpretation and communication is thus widely acknowledged [810]. 


\section{Insert Figure 1 here}

Figure 1. Use of the terms "forecast," "projection" and "scenario" in a large sample of digitised books published in English. The vertical axis shows frequency of use of each case-insensitive word as a percentage of all words. Source: [2].

Whether explicitly, through a reasoning process, or implicitly, energy scenario developers choose smaller, more tangible sets of scenarios from this potentially infinite range of possibilities. Generally, quantitative scenarios are constructed using one of two approaches [11]: (i) a scenario matrix is formed from the key uncertain factors, e.g. fossil fuel price, [12] and then energy models are run using these factors as modelling inputs to quantify these scenarios; or (ii) specific, desired energy system outcomes are predefined and then conditions and decisions needed for these outcomes are elicited through model runs. To date, the choices of these key uncertain factors or scenario outcomes and thus scenarios are often based on subjective judgements about their relevance $[9,13,14]$. But there is increasing interest in using systematic, formal techniques to facilitate the choice of scenarios [15]. These techniques, for example, can help choose scenarios with the most influential uncertain factors [8], the most internally-consistent combinations of the factors [12, 13, 16-19], maximally-different/diverse scenarios [20-23] scenarios that illuminate key vulnerabilities and robust responses [24, 25], and scenarios developed through stakeholder engagement or chosen by scenario users themselves [26-29]. Even with these techniques to guide scenario choice, it is often unclear what types of scenarios are adequate and why. As these methods develop, it is useful to reflect upon and assess past practice in scenario choice.

Although often subjective, and at times even arbitrary, how we choose which scenarios on which to focus analysis is important. Scenario choice reflects the 
uncertainties that scenario developers consider important and wish to communicate to the users of those scenarios. When energy scenarios are developed, they always include a large number of assumptions; those that are highlighted through scenario choice inevitably receive most attention, while others remain hidden [30]. For example, scenario developers who assume that oil price is the key uncertain factor in a transport system transition would likely choose scenarios of lower and higher oil prices; in this way, they express a view that this is the key uncertainty. Yet, other scenario developers may construct scenarios of high and low climate change mitigation efforts in the transport sector; the emphasis of these scenarios would therefore be very different. Of course, such choices are not always purely 'analytic' and they may also be made for political or strategic reasons. Depictions of the future are frequently an ideological or political battleground, and while some analysts may wish to use scenarios as an analytic construct to deal with deep uncertainties, others use scenarios to advance a particular perspective.

By conducting a retrospective analysis of twelve national-level UK energy scenario exercises (1978-2002), this paper focuses on the past choice of energy scenarios, in order to provide insights for future scenario choice. It explores which factors were chosen in the development of scenarios between 1978 and 2002, paying particular attention to the historical context and institutional developments that influenced these choices. The paper then analyses whether these factors for scenario choice turned out to play as central a role in the actual system transition as had been anticipated by the scenarios. This retrospective approach allows for gathering insights, which not only helps to improve the choice of future energy scenarios, but also to improve the aforementioned formal techniques for scenario choice.

\section{Overview of generic scenario methodologies}


There is a wide range of literature on the generic field of scenario studies, methodologies and typologies. Bradfield et al. [31], for example, highlight the lack of consensus on the definitions, principles, characteristics, and methodological ideas about scenarios. In their paper these authors structure the scenario methodologies into "the USA centre" (including the intuitive logics school and the probabilistic modified trends school) and "the French centre" that relies on the approach called La Prospective. The intuitive logic methodology differs from the other two in that the other methodologies are likely to be used for exploratory, rather than normative, exercises. Similarly, intuitive logic methodology is less focused on quantitative outcomes: it is more process orientated and also produces qualitative, not quantitative, outcomes. Amer et al. [32] follow the same general division, but focus their review on quantitative approaches.

The strengths and weaknesses of the different methodologies are reflected in the scenario development processes and outcomes. Huss and Honton [33] argue that the qualitative nature of the intuitive logic methodology allows "a careful tailoring" of scenarios to the specific case, but is less suitable for a scenario environment that requires a quantitative approach. The probabilistic modified trends methodology, on the other hand, allows a combination of quantitative methods with qualitative factors, but generally focuses on a more narrow scope, such as one key decision variable $[31,33]$.

Börjesson et al. [34] also review a range of scenario typologies and then present their own variation, the structure of which is initially based on the type of question the analysis is supposed to answer: "what will happen?" (predictive) vs. "what can happen?" (explorative) vs. "how can a specific target be reached?" (normative), and subsequently on finer refinements of the original questions. The normative approaches are then divided into preserving (e.g. optimising modelling) and transforming (e.g. backcasting) scenario studies. Depending on the nature of the scenario study (predictive, explorative 
or normative), Börjesson et al. [34] suggest different techniques for generating the knowledge, data and ideas needed for the scenarios (e.g. Delphi methods, surveys workshops), for integrating individual scenario elements into the whole (explanatory and optimising modelling, time series analysis), and for ensuring the consistency of the scenarios (morphological field analysis, cross impact analysis). This typology of scenarios is also adopted for a retrospective analysis of UK energy scenario analysis (1978-2002).

Van Notten et al. [35] propose a typology of scenario techniques based on the goal of the study (exploration or decision making), project design (intuitive or formal) and scenario content (complex or simple). Wilkinson and Eidinow [36] classified techniques on the basis of two axes: low to high systems uncertainties and low to high decision stakes. There are many other classifications too.

In a parallel stream to the methodological classifications, there has been a growing interest in assessment of scenario methodologies and scenarios, cf. [30, 37-40]. Scenarios can be assessed from a narrow view of scenarios as products or broader view of scenarios as processes tailored to the specific question and multi-stakeholder setting [37, 40]. Whether in the generic scenario field or in the energy scenario research, to date little attention has been paid to how scenarios are chosen from the infinite number of plausible scenarios that can be constructed. This paper thus aims to retrospectively assess scenario choice.

\section{Retrospective analysis method}

For this retrospective analysis, a systematic search of the UK energy scenario literature was conducted. The first literature source with UK energy scenarios was published in 1978. Littlechild et al. [41] state that by 1980 more than 40 energy models existed, which could be used to developed scenarios of the national UK energy system or 
its sub-systems. However, many of these models were within the realms of governmental organisations or the energy industry. Therefore, they were not published for wider audiences and were not available for this analysis. All references to UK energy scenarios, forecasts and projections between 1978 and 1985 were examined. Five references were then chosen for more detailed retrospective analysis because they were considered the most influential. That is, they underpinned the key UK energy policy documents or were referenced and discussed by other UK energy scenario developers. After 1985, as the number of energy scenario references increased to more than one hundred, only national energy scenario exercises, i.e. those developed by governmental or other influential organisations, were analysed in detail. The year 2002 was chosen as the final year of this ex-post analysis because firstly, the UK Energy White paper in 2003 changed the course of UK energy policy by emphasising importance of climate change mitigation [42] and secondly, because the scenarios after 2002 can be assessed retrospectively only to a limited extent.

This retrospective analysis aims to capture how and why the specific UK energy scenarios were chosen, which factors were considered to be key uncertainties for scenario construction, and whether these factors retrospectively turned out to be important. Methodologically, three approaches are merged. First, in line with [40], the paper explores how the UK energy scenarios evolved within the broader contextual developments, described in [41-43]. Second, scenario exercises and the produced scenarios are classified on the basis of the typology by Börjesson et al. [34]:

- Predictive (probable) scenarios are defined as forecasts or what-if scenarios that address the question what will happen under the conditions of likely development or some specific developments. 
- Explorative (possible) scenarios are defined as external or strategic scenarios that address the question what can happen in terms of external developments or if the current strategies are maintained.

- Normative (preferable) scenarios are preserving or transforming scenarios that answer the question how can a specific target be reached by changes in the current situation or prevailing structures.

As will be discussed in Section 4.1, many scenario studies include mixes of scenario types, for example that explore the need to reach normative policy goals (normative elements), while explicitly accounting for uncontrollable external factors (explorative elements). Scenarios are thus classified on the basis of their primary, dominating type.

Third, following [44-47], the past UK energy scenarios were compared with actual developments [43]. Scenarios-in contrast to forecasts or projections-attempt to depict several plausible futures rather than to accurately predict the future. Thus, these past UK energy scenarios are assessed not on the basis of their accuracy to the actual transition, but on two guiding questions: firstly, did the scenario set adequately map the scale of uncertainty? And, more specifically, did the scenario set encapsulate the resulting future in terms of both input parameters and outturn of key energy system attributes? Secondly, in seeking to identify whether the scenario set addressed the uncertainties and drivers that did indeed turn out to be critical, the paper asks whether, if building historical counterfactual scenarios, one would use the same set of scenario factors as the original authors. In this way, this analysis asks whether the choice of key scenario factors proved to be useful descriptors of the historical branching points.

The UK energy scenarios developed during 1997-2002 were at the early stages of the methodological and conceptual developments of energy scenario frameworks. This type of thinking was just starting to emerge (Figure 1). Furthermore, Strachan [48] 
argued that in 2003 the UK's energy systems modelling and analysis capacity was underdeveloped. This paper thus does not criticise past UK scenarios, but rather looks at how learning from past experiences can help us to make better choices when selecting scenarios.

\section{Results}

\subsection{Scenario choices in the past UK exercises}

The twelve UK energy scenario exercises (1978-2002) analysed in this paper are summarised in Table 1. The first national future energy study appeared in in the UK in 1978 in the face of growing energy security concerns following the first oil crisis in 1973. While this study adopted the forecasting approach, the wider methodological shift (Figure 1) led to more and more scenarios being developed per exercise. This section further introduces the analysed scenario exercises in detail and their scenario choices.

\section{Insert Table 1 here}

Table 1. Summary of past UK energy scenarios analysed

\subsubsection{UK Green Paper on energy, 1978}

After the first oil crisis in 1973 and the UK's North Sea oil exploitation, which began in 1975, there was strong concern about oil dependence and the lack of strategy to address it. Thus, in 1973, the UK Department for Energy was established. In 1978, the department released the UK Green Paper on energy [49]. The aim of this Green Paper was to "set out the Government's energy strategy proposal... It is intended that the strategy will be kept under continuing review" [page iv, 49]. A single predictive "forecast" was produced, extrapolating the trends of $2 \%$ economic growth and growing energy prices. 
Despite there being only one forecast, the Green Paper argued that it covered "a wide range of possible futures" [page 84, 49]. Adopting the scenario view prevalent today (Figure 1), this statement looks ironic as at least two scenarios are needed to represent a range rather than a single future point. This Green Paper sparked discussion about energy futures in the UK and was followed by numerous alternative scenarios developed by other organisations.

\subsubsection{Low energy strategy by the International Institute of Environmental Development} (IIED), 1979

In response to the high demand forecast by the 1978 Green Paper, the research institute, the IIED, published their UK energy scenarios with the aim to "present a different view of the future... [one which shows] how the United Kingdom could have 50 years of prosperous material growth and yet use less primary energy than it does today" [page 9, 50]. The IIED analysis was based on a detailed, sectoral bottom-up model, which considered more than 400 energy use categories. Bottom-up models have a detailed representation of energy supply technologies and demand in various sectors [53]. They optimize total energy system costs, including investment, operation \& maintenance, and fuel costs, under various technology and policy constraints. The IIED demonstrated two scenarios of low and high economic growth, and argued that economic growth was possible with low energy demand due to energy conservation measures, saturation effects etc. These scenarios are thus classified as normative.

\subsubsection{Scenarios of the Friends of the Earth (FoE), 1982}

FoE, an environmentally-focused non-governmental organisation, also contributed to UK energy strategy debate with scenarios produced around 1979. 
Although these scenarios were widely discussed in secondary sources as feedback to the UK Green Paper on energy 1978, the original source could not be found. Thus, these scenarios are analysed based on a secondary source that was published at a later date [51]. The FoE scenarios were normative and aimed to demonstrate the vision of low energy demand in the UK through two energy scenarios: "technical fix" and "conserver society." Both of these scenarios envisioned a radical fall in UK primary energy consumption due to energy conservation and a shift to renewable energy ("technical fix") or due to even more radical conservation efforts ("conserver society").

\subsubsection{Update on the previous Green Paper, 1979}

In light of IIED, FoE and other scenarios, in 1979 the UK Department of Energy updated the Green Paper on Energy. The initial single forecast had been critiqued for its prescriptive nature and high demand growth assumption. The 1979 scenario was framed more cautiously: "not [as] predictions of what will necessarily happen nor prescriptions of what would happen. The projections are, however, intended to provide a broad quantitative framework for the consideration of possible energy futures and policy choices" [page 1,52]. In this document, two cases of low (2\%) and high (3\%) economic growth were considered, leading to explorative type of scenarios. At the same time high oil prices, energy conservation efforts, and low deployment of renewables were assumed.

\subsubsection{Birmingham Energy Model (BEM), 1982}

The BEM, developed at the University of Birmingham, was the first and, at that time, only large-scale, computer-based, bottom-up model of the whole UK energy system [41]. The development of this model started in 1974, just after the first oil crisis and, as such, the model represented state-of-the-art research, c.f. $[54,55]$. The aim of the model 
was "to calculate and compare optimal strategies for the UK energy sector... to evaluate some current proposals for UK energy strategies in the light of the model's results" [page 1,41]. Due to the explicit reference to optimal strategies, the BEM scenarios are classified as normative. BEM embraced a number of existing assumptions for developing scenarios, including high demand growth scenarios from the 1978 Green Paper and low demand scenarios from the IIED. The authors also considered scenarios with and without nuclear power, which may have been a response to growing concerns about nuclear energy following the 1979 Three Mile Island accident.

\subsubsection{MARKAL for renewable energy programme at the Energy Technology Support Unit,} $\underline{1994}$

From 1982 to 1994, few publicly available, national energy scenarios were developed in the UK. Due to growing environmental concern about sulphur and nitrogen oxides from coal power and climate change, energy scenario exercises were undertaken once more in 1994. A computer-based, bottom-up model, based on the MARKAL platform [55] and covering the whole UK energy system, was developed by the Energy Technology Support Unit (ETSU). In the scenario exercise, commissioned by the UK Department of Trade and Industry (DTI), MARKAL produced scenarios for analysing the potential role of renewable energy strategies in the UK and the needs for research and development strategies [56-59]. A total of 18 scenarios were constructed, which considered a matrix of three levels of discount rates $(8 \%, 15 \%$, and varying rates of $10-25 \%)$ and six types of scenarios: (i) high oil and gas prices, (ii) composite of conventional demand growth and oil and gas prices, (iii) low oil and gas prices, (iv) heightened environmental concerns without nuclear, (v) heightened environmental concerns with nuclear, and (vi) oil and gas price shocks. Although the MARKAL model produces scenarios using cost 
optimization, the ETSU 1994 scenarios are considered primarily as explorative because they did not include explicitly include normative goals, such as ambitious emission cuts. Although the whole energy system was modelled by MARKAL, results were only presented on the uptake of individual renewable electricity generation technologies, under different scenarios. It was concluded that different types of renewable technologies get deployed to different extents under the 18 scenarios.

\subsubsection{DTI Energy Projections for the UK, 1995}

The DTI energy projections [60] were a tool to monitor the development of UK energy markets. As climate negotiations gathered pace, the DTI projections also aimed to reflect whether the UK was on course to meet its international commitments to limit greenhouse gas (GHG) emissions. Due to the focus on exploring most likely developments and accounting for some external uncontrollable factors, these scenarios are classified as explorative. The energy demand projections were based on an economic demand model that used economic growth and fuel price assumptions as inputs and quantified the future demand scenarios on the basis of historical trends and known new policies. The electricity sector was based on a bottom-up, cost optimisation model. In order to consider a range of possible developments, six scenarios of high (2.75\%), central (2.25\%) and low (1.75\%) economic growth, as well as high oil price of $20 \$(1999) / b b l$ or low price of $10 \$(1999) / \mathrm{bbl}$. This was expected to "both encompass the likely range of possible outturns and, as importantly, indicate where the major uncertainties could arise." [page $14,60]$.

4.1.8. MARKAL for renewable energy programme at the Energy Technology Support Unit, 
In 1999, the DTI commissioned another MARKAL study to inform the update of the UK renewable energy programme [61]. While the individual renewable energy technologies for electricity generation were analysed in detail, MARKAL model runs were used to produce explorative scenarios to capture the market structure and how it would impact the deployment of renewables. Ten scenarios were analysed; all assumed the central economic growth case (2.25\%), but the scenario matrix was formed to capture the high (15\%) and low discount rates (8\%), GHG emission constraints $(10 \%$ or $20 \%$ lower by 2010), and minimum levels of renewable electricity (none or $10 \%$ in 2010 ). The results were provided for individual renewable energy technologies.

\subsubsection{MARKAL for climate change mitigation by the DTI, 1999}

In 1999, the MARKAL model was also used in another DTI study to "examine the most cost-effective combinations of fuels and technologies" [page 1, 62] for mitigating carbon dioxide, sulphur dioxide, nitrogen oxides and other emissions from the energy sector [62]. The scenarios referred to low, central and high demand growth, high and low fossil fuel prices, and scenarios with and without nuclear. Under all of these scenarios, it was assumed that the emission mitigation goals were met and the implications of these developments were analysed. Thus, these scenarios are considered as primarily normative (although they also include elements of explorative scenarios) because they explored what changes are needed to meet the emissions goals.

\subsubsection{DTI Energy Projections for the UK, 2000}

In 2000, the DTI produced an updated version of the 1995 projections [63]. These updated projections used the same type of model and the types of scenarios as in the Section 4.1.7, but updated some model parameter values due to new trends. 


\subsubsection{1. "Energy-the changing climate" report by the Royal Commission on Environmental}

\section{Pollution (RCEP), 2000}

The report by the RCEP [64] that advised the UK Government, Parliament and the Queen on environmental issues made the very influential conclusion that UK carbon emissions should fall by $60 \%$ by 2050 in order to avoid the worst impacts of climate change. The report was of a normative nature and argued that "there is a moral imperative to act now" (page 50) and listed "actions that can and should be taken by the government and by other parties in the UK now" [page 3,64]. The report used four scenarios "to highlight the nature of the choices available for the UK" (p. 171). These scenarios combined constant, low and very low energy demand levels, high uptake of renewables, and with or without nuclear power and carbon capture and storage (CCS). These scenarios were not presented as complete pictures; that is, the primary energy demand and technology portfolios for the scenarios were not given. The report listed only various individual requirements to achieve GHG reduction targets through energy demand reduction and the deployment of low-carbon technologies.

\subsubsection{The Energy Review by the Performance and Innovation Unit, 2002}

With the 2002 Energy Review, the UK Government aimed to "initiate a national public debate about sustainable energy, including the roles of nuclear power and renewables" [page 6, 65]. The Review listed lessons from five scenarios that included a Business as Usual scenario and four others, which were arranged around the scenario matrix of globalism versus regionalism and commercialisation versus community. Since the scenarios all met the $60 \%$ emission mitigation target by 2050 , they are classified as primarily of normative nature. 


\subsection{Scenario choices in the historical context}

As shown in Table 1, the majority of the energy scenario exercises analysed resulted from UK government departments i.e. the exercises were either conducted or commissioned by government. Greater diversity is visible in the period between 1978 and 1985, because our analysis was able to capture all energy scenario exercises. After 1985 , however, the greater number of scenario exercises analysis meant the analysis was only able to focus on influential scenarios, and as a result government studies were the main focus.

A methodological shift can be noticed in the period 1978-2002. In line with Figure 1, the scenario studies shifted from the early predictive type of scenarios to more cautious explorative scenarios or instrumental normative scenarios. The latest scenarios are explorative or normative, depending on whether they aim to set the external factor scene for decisions or to define what needs to be done to achieve a specific goal. In parallel, the scenario development method shifted from extrapolation-type techniques to modelinformed studies, since models can account for energy system changes beyond extrapolation of past trends and can analyse the feasibility of normative goals.

In terms of why the specific scenarios were chosen, there are limited methodological descriptions in the analysed studies. On the one hand, most of the analysed scenarios are government reports that may have shorter methodology sections than would be common in peer-reviewed academic literature, for example. On the other hand, all these studies seem to be driven by experts or well-informed stakeholders (e.g. FoE), meaning that scenarios were chosen on the basis of their views of what the key uncertainties were and what uncertainties should be drawn attention to, but not necessarily using formal scenario techniques. As discussed in Section 1, such formal 
techniques have only more recently received attention. None of the analysed studies appear to be based on formal stakeholder or public engagement, which has become more prevalent in recent years, cf. $[29,66]$.

Table 2 compares the scenario matrices of the twelve UK energy scenario exercises analysed for this paper. The table shows that scenario choice evolved during the period 1978-2002, and that the factors used to construct scenario matrices also shifted. The choice of scenarios was responsive to the historical context and reflected contemporary debates.

\section{$<$ Insert Table $2>$}

Table 2. Key factors in scenario matrices, 1978-2002.

The first oil crisis in 1973 and the initiation of the UK's North Sea oil exploitation in 1975, led to the first UK Green Paper on energy in 1978. After the second oil crisis in 1979 , and as concern grew about unstable oil prices and societal vulnerability due to ever increasing energy demand, the scenario exercises of the 1970s and 1980s primarily varied the economic growth, energy conservation efforts and fossil fuel price assumptions. After the Three Mile Island accident in 1979, and following Chernobyl in 1986, multiple scenario exercises began to incorporate scenarios without nuclear power. After the 1988 North Sea oil platform of Piper Alpha disaster, and following the requirement to reduce nitrogen oxide and sulphur oxides emissions from coal power plants as required by the Large Combustion Plant Directive of the European Communities, UK energy scenario exercises also began to consider scenarios with high deployment of renewable energy. MARKAL 1994 also reflected upon nitrogen oxides and sulphur oxides emission constraints. At the same time, global momentum on climate 
change gathered pace, leading to the 1992 UN Framework Convention on Climate Change and the 1997 Kyoto Protocol. Therefore, after 1997, all of the energy scenario exercises referred to climate change; most exercises included emissions mitigation in the scenario matrix or, in the case of 2000 Energy Projections, assessed the scenario results in light of emissions reduction targets.

Although the scenarios were responsive to ongoing developments, an apparent process of 'lock-in' of specific scenario factors can be observed. The review of how and why the specific scenarios were developed shows that many energy scenarios crossreferenced or responded to other scenarios. For example, the 1979 IIED Low Energy Strategy and 1982 FoE scenarios explicitly stated that they depicted low energy demand scenarios that were an alternative to the high demand forecast from the 1978 UK Green Paper. The updated 1979 UK Green Paper presented scenarios that took into account the feedback from IIED, FoE and other scenarios. The 1982 BEM scenarios also used the 1979 UK Green Paper and IIED scenarios as assumptions to inform the scenario matrix. In addition, BEM included a new scenario factor of "no nuclear," possibly in response to the Three Mile Island accident. Finally, the 2000 DTI UK Energy Projections were updates of the 1995 Energy Projections, and were based on the same scenario matrix.

Table 2 shows that the scenario matrix factors vary across different exercises and over time. For example, the 2000 DTI UK Energy Projections concentrate on the scenarios of growth and fossil fuel prices, the 2000 RCEP report focuses on the scenarios of energy conservation efforts, nuclear and CCS deployment, and climate change mitigation, while the 2002 Energy Review includes the different governance scenarios. Thus, the most comprehensive, diverse coverage of scenario matrix factors is achieved across the multiple scenario exercises. These scenario exercises are also developed by governmental, non-governmental, research and independent organisations, which is an 
asset because they appear to choose different matrix factors. However, as energy scenarios are developed using quantitative models, almost all factors from Table 2 refer to modelling parameters or outcomes, such as economic growth, fossil fuel prices or GHG emissions. This may be a limited scenario choice because it allows for capturing the parametric uncertainty, rather than structural uncertainties; definitions of the parametric and structural uncertainty are discussed in detail in [67]. With the exception of the 2002 Energy Review, which looked at structural governance changes, all the scenario factors from other exercises can be straightforwardly used as modelling parameters.

\subsection{Scenario choices and the actual UK energy system transition}

\subsubsection{Did the scenario choices encapsulate the actual transition?}

Scenarios aim to depict several plausible futures rather than to accurately project the future. Here, they are assessed retrospectively on the basis of whether they adequately mapped the scale of uncertainty and captured key drivers and trends in the transition of the UK energy system.

Figure 2 compares seven of the past energy scenario exercises with the actual energy system transition; only seven exercises were chosen because their publications provide the complete primary energy demand structure, while the publications of others omitted this detail. It assesses these scenarios in terms of primary energy demand, which was chosen as a metric because these values were reported in most of the analysed references (see Table 1). As argued in Section 4.2, Figure 2 also shows that the richest representation of uncertainty in the primary energy demand is achieved when all seven scenario exercises are combined. Some scenarios are extreme, especially the initial high 
economic growth scenario from the 1978 Green Paper and the visionary FoE scenarios. If one wants to capture maximally different possibilities, or the whole "scenario trumpet" [68], these types of scenarios add a valuable, albeit extreme perspective. Diversity in perspective leads to diversity in futures considered.

\section{Insert Figure 2 here}

Figure 2. Comparison of the actual primary demand transition (black line) and selected past UK energy scenarios in terms of primary energy demand, Mtoe

Figure 2 also shows that the scenarios explored using the technology-rich, costoptimising BEM model covered the widest range of futures, when compared to the other approaches. This is primarily due to BEM basing the scenario matrix on the earlier assumptions of the 1979 Green Paper and the IIED Low Energy Strategy. The 1982 BEM scenario with the steepest primary energy demand growth was the new "no nuclear" scenario that had not been considered by previous scenario exercises. By contrast, the DTI Energy projections of 1995 and 2000 were limited to the scenario matrix of economic growth and fossil fuel price only. This lead to a comparatively narrow representation of the uncertainty (Figure 2); the resulting trend lay outside the projected scenario envelope.

Collectively the analysed past UK energy scenarios from Figure 2 encapsulated the overall trend in primary energy demand, but they did not necessarily capture the drivers. For example, the scenarios from the 1970s and 1980s assumed relatively high economic growth (even in their low growth scenarios), which did not materialise [43]. The 2000 DTI Energy Projections also failed to consider a possible economic crisis, such as the global economic crisis of 2008. In terms of fossil fuel prices, only high oil prices were 
considered by the scenarios developed in the 1970s and 1980s, while in practice prices fluctuated [43].

Figure 3 shows the structure of the primary energy demand by source for the scenario exercises carried out in the 1970s and 1980s. In general, all of the scenarios expected a greater role for coal in the energy supply mix; the scenarios did not anticipate the environmental concerns over sulphur oxide and nitrogen oxide emissions that arose during the 1990s. The role of gas in the energy mix was also underestimated; in the 1980s, coal was considered to be an adequate fuel for electricity generation, while gas was seen as too high quality a fuel for electricity generation. The UK began gas production in 1967 and oil production in 1975, which did not peak until 2000 and 1999 respectively, and the scenarios did not always focus on substantial reduction of these fuels. As Figure 3 demonstrates, the further into the future the scenarios reached, the more pronounced the deviations from actual evolution of the energy system. These scenarios reflected the mainstream mindset of the 1970s and 1980s, which became an increasingly poor description of the energy system.

\section{Insert Figure 3 here}

Figure 3. The primary demand structure in 2000 and 2025 from the Green Paper (1978), IIED Low Energy Strategy (1979), Updated Green Paper (1979) and Birmingham Energy Model (1982).

\subsubsection{What scenario choices for the past would be made today?}

The benefit of hindsight allows not only the identification of the uncertain factors of the energy system that were and were not captured (Section 4.2), but also for a more general assessment of the scenario choices. We ask whether, if one were to build 
historical counterfactual scenarios today, one would use the same set of scenario factors as the original authors.

First of all, in the 1980s and 1990s, the UK energy system underwent a major governance change to electricity and gas markets through privatisation and liberalisation. This had a substantial influence on the energy demand, but particularly energy supply [42]. None of the scenario exercises from that time considered this shift in governance. Instead, the scenarios focused on uncertainties that, in retrospect, appear less interesting as drivers of system development than the governance and regulatory changes that actually occurred. The 1982 BEM was used before market liberalisation, while MARKAL 1994 and 1999 were for developing scenarios after liberalisation. However, despite similarities in the model structure and rationale, neither scenario choices (Table 2) nor the model structures reflected this shift in governance. This raises the question of whether the scenario developers turned a blind eye to the broader institutional developments because modelling parameters could not easily capture them or whether they thought that the inclusion of these structural changes would not affect the scenarios. The 2002 Energy Review did include governance-focused scenario factors, through regionalisation versus globalisation and commercialisation versus community. This may have been a post-hoc recognition of the importance of governance changes.

All of the analysed scenario exercises from Table 2 assumed consistent economic growth; scenarios encompassed high and low growth, but the assumed trend was for stable and smooth growth. Further, in the 1970s and 1980s, all of the scenarios assumed continued high or very high fossil fuel prices. However, the actual economic growth rate and fossil fuel prices fluctuated [43]. The scenarios did not consider periods of economic decline or decreases in fossil fuel prices and in this way did not adequately represent the scale of uncertainty. Eventually, the 2008 economic crisis led to a substantial drop in 
energy demand. With the exception of MARKAL 1994, the models also assumed smooth curves for uncertainties (e.g. high or low price), but in reality prices and growth rates fluctuate. Acknowledgment of fluctuations in these key drivers could have improved scenario formulation.

Throughout the period analysed, the UK also underwent a major structural change which saw heavy industries close down or move outside the country [42]. This not only affected overall energy demand, but also the technology mix as heavy industry is linked to centralised, large-scale technologies such as coal power plants. Yet, these structural changes were barely referred to in the scenarios.

A similar pattern is observed in the case of the GHG emission mitigation scenarios, considered by the majority of scenario exercises after 1997. While the UK GHG emissions from the energy sector decreased between 1990 and 2010 [69], this reduction was not driven purely by concerns about climate change. The aforementioned economic crisis, structural shift and the switch from coal to other fuels to address local air pollution concerns, also contributed substantially to emission cuts. While scenarios in the 1990 s and early 2000s have continued to focus on climate policy as the major driver of GHG emissions reductions, other factors, such as structural shifts and economic decline, have proved more important in driving such changes. Without these structural changes and economic crises, emissions mitigation targets may not have been met, yet none of the scenarios in 1990s and early 2000, except the DTI Projections, considered scenarios of non-mitigation.

In terms of technology deployment, especially in the case of nuclear, many of the scenario exercises considered extreme scenarios; for instance, with unconstrained nuclear electricity generation and without. For such contested technologies extreme policy decisions of, for example, phase out could be made; such decisions were taken in 
Germany and Switzerland in 2011. However, historical trends in the UK showed that government strategies oscillated between support for and negligence of nuclear energy [42]. Eventually, the actual deployment of nuclear power has neither been equal to zero nor has it constituted a substantial share of the technology mix. The insight here depends on the aim of the scenario exercise: if the goal is to construct scenarios that are likely to occur, then it is better not to use extreme scenario factors "with nuclear" and "without nuclear"; conversely, if the goal of scenarios is to explore various possible future developments, the extreme scenarios, such as "without nuclear," can still be useful. For example, the "no nuclear" scenario by BEM in 1982 was the only scenario of its time to anticipate the emerging role of natural gas. While the "dash for gas" in the UK occurred primarily due to local air pollution concerns, which led to a reduced role for coal [42], the disabling of the nuclear option in the BEM scenarios drew attention to the potential role for gas. The flawed assumption that gas was too valuable to play a significant role in electricity generation was revealed by the "no nuclear" scenarios of the BEM. In this way, the "no nuclear" scenario was useful to explore a variety of other possibilities, even if the scenario itself was less likely.

\section{Informing future scenario choice}

Today's developers of national energy scenarios in the UK and elsewhere face many of the same challenges as our predecessors, since scenarios explore 20,30 or 40 years into the future $[70,71]$. This section reflects on the lessons from this analysis for future energy scenario choices [72].

\subsection{Looking beyond parametric assumptions and today's concerns}


All of the past UK energy scenarios that were analysed (Table 1) were tightly linked to and influenced by the key concerns and discussions of the time. The oil crises of the 1970s, and concern about unstable oil prices and societal vulnerability due to evergrowing energy demand, led to a focus on economic growth and fossil fuel price in the construction of the scenarios. These scenarios thus mirrored the key concerns of the time. The scenarios focused on the parametric uncertainty around economic growth rate and exact fossil fuel prices, but forwent important structural uncertainties of industrial change, strengthened environmental concerns, and shifts in governance. Thus, future energy scenarios should not only focus on parametric uncertainties, but should also reflect the plausibility of wider structural changes [13].

\subsection{Accounting for the role of multiple actors and governance}

Between the late 1980s and the early 2000s, the UK energy system underwent a major governance change that was not reflected in any of the scenarios. Today's energy challenges call for different governance arrangements and thus future governance shifts may be anticipated $[73,74]$. In the development of future energy scenarios, it is thus advisable to consider the potential influence of governance and the decision-making of key actors $[70,75,76]$. This poses a methodological challenge, one which requires the linking of plausible governance arrangements with quantitative energy models. This challenge might be addressed through systematic scenario choices [76] or through approaches that combine insights from qualitative and quantitative scenarios through 'soft-linking' or scenario-model dialogue $[77,78]$.

\subsection{Considering failures and policy priority shifts}


With the exception of Energy Projections 1995 and 2000, all scenario exercises after 1990 incorporated an assumption of climate change mitigation and none considered scenarios of mitigation failures. Here a parallel could be drawn with the economic growth assumptions. While both climate change mitigation and economic growth are important to national agendas, that does not necessarily mean that policies will lead to positive outcomes i.e. emissions reductions and sustained economic growth. All of the scenario exercises examined here assumed continued economic growth, which did not happen, and none considered an economic downturn. It is thus possible that the current focus on climate change mitigation may prove to be similarly unhelpful in terms of characterising the key drivers of future system change. Mitigation failure scenarios are thus recommended to counterbalance mitigation scenarios [79]; for example, through extended economic downturns, disruptive behavioural change, or policy and technological failures. There is also evidence of a shift in focus away from climate change, towards one that reflects the 'policy trilemma' of climate mitigation, affordability, and supply security $[80,81]$. The implications of such a shift for efforts to decarbonise the economy remain largely unexplored in energy scenarios to date.

\subsection{Not only considering black-or-white assumptions}

When concerns about the safety of nuclear power sharpened in late 1970s, multiple scenario exercises began to include 'no nuclear' scenarios. However, in the event neither the complete phase-out of nuclear power nor a significant increase took place. More recently, the focus on climate mitigation and uncertainties around the deployment of CCS has led to the consideration of the scenarios with and without CCS. Here, parallels with nuclear power can be drawn; although in the case of CCS, the uncertainty also includes the concerns related to new technologies reaching commercial viability. 


\subsection{Uncovering unexpected knowns}

With regard to gas, the majority of UK energy scenarios carried out in the 1970s and 1980s did not consider the possibility of a significant increase in gas. Yet, the 1990s saw the UK undergo a "dash for gas". The deployment of gas-fuelled power generation was not the "unknown unknowns" or the "surprise" type of uncertainty [82, 83], because the technology and its characteristics were widely known $[84,85]$. Rather, the prevailing consensus, that coal was the most appropriate fuel for power generation, led scenario developers to overlook the possibility of substantial gas use. This provides an example of an "unexpected knowns" or "surprising knowns" type of uncertainty. Today's scenario developers should also reflect upon whether some consensus knowledge, such as the limited use of renewable energy due to their intermittent nature, may eventually turn out to be "unexpected knowns".

5.6. Adopting a multi-organisation, multi-method and multi-scenario view

The long-term future of the energy system is inevitably surrounded by multiple uncertainties. Table 1 shows that, taken together, past UK energy scenario exercises by different organisations covered the richest and widest range of uncertainty and potential energy system outcomes. Even the more radical scenarios, such as those of environmentally-focused non-governmental organisation FoE, are valuable if the aim is to capture a broad range of possibilities. Indeed, it is noteworthy that the FoE scenariosseen as radical and extreme at the time-were closer to describing the ultimate evolution of primary energy demand than was the official government forecast in the 1979 Green Paper. While there are inevitable trade-offs between descriptions of uncertainty and the strength of individual narratives, such a multi-organisation, multi-method and multi- 
scenario matrix approach has clear benefits. If that cannot be achieved, then feeding inputs from multiple organisations into an energy system model, such as the 1982 BEM, can lead to coverage of a wider range of uncertainties. This could take the form of interactive scenario choice or, especially when process matters, development with stakeholders or decision makers, c.f. $[28,29,86]$.

A cautionary remark must be added here on scenarios that cross-reference and respond to one other, which may lead to the consideration of a narrower range of futures. As shown in Section 4.3.1, the 1978 UK Green Paper led to several other publications, which critiqued this scenario. When the Green Paper was updated in 1979, it sought to accommodate the range of perspectives suggested by other organisations, and eventually covered a much narrower range of potential futures (see Figure 2). Thus, while discussion and feedback help to improve the quality of individual scenarios, it may also narrow down the range of futures considered.

\subsection{Diversifying and iteratively revising scenarios}

Finally, Figures 2 and 3 show that, in the shorter term, energy scenarios can encapsulate the actual energy system transition, but as they look further into the future, the uncertainties grow and the differences between the scenario results and the actual trajectory deviate. Despite this, scenarios remain essential tools for strategic decision making, policy development and assessment. Also, by definition they are meant to provide alternative futures rather than a single prediction. In the absence of better tools for thinking about potential energy futures, energy scenarios will remain important. In order to improve their relevance and to reduce the sensitivity of the scenario choices to dominant contemporary debates and assumptions, as well as the other limitations discussed in this paper, their iterative revision is essential. Careful thought needs to be 
given to avoid lock-ins, wherein similar scenarios are constructed despite changes underway in the energy system and wider context. Instead, changes in scenario matrix factors could help diversify the ways in which we view, conceive and think about energy futures c.f. [87].

\section{Conclusions}

Due to multiple uncertainties and complexities in the energy system, the scenario approach is widely used for long-term analysis at a national scale. While there are infinite amounts of plausible scenarios that could be constructed, scenarios developers choose smaller, more tangible sets of scenarios. The choices made are critical since scenarios help to highlight and communicate the key uncertainties and system drivers. In order to better understand how such scenario choices are made and how they could be improved, this paper conducted a retrospective review of UK energy scenarios carried out between 1978 and 2002.

In terms of the process of choosing scenarios, the retrospective analysis shows that the richest and widest picture of uncertainty -in the energy system transition and its drivers-is captured through merging the scenarios developed by multiple organisations. Even then caution is necessary because through discussion and feedback consensus on specific expectations for the future (e.g. high oil price, high economic growth, GHG emissions mitigation) may emerge and narrow down the range of possibilities considered. In terms of choosing factors for scenario matrices, this retrospective review shows that scenarios tend to reflect contemporary discussions, concerns and expectations. Meanwhile, scenarios tend to ignore other, equally important aspects that either cannot be so easily modelled as parameters, such as governance arrangements or structural changes in industry, or for which there is a consensus that 
they are not likely, for example, the deployment of gas power plants in the 1990 s. Although "unknown unknowns" and surprises will shape the energy system transition, these are almost impossible to anticipate, rather this retrospective analysis demonstrates the importance of considering "unexpected knowns". These "unexpected knowns" are more easily thought of, but may be constrained by the wider consensus among scenario developers.

This paper therefore invites energy scenario developers to maintain analytical diversity in scenario approaches and the chosen factors for scenario matrices. In current scenarios exercises, parallels with the UK energy scenarios of 1978-2002 point to the need to reflect on critical factors, such as governance changes, fluctuations in economic growth and the price of fossil fuels, climate change mitigation success and failure, intermediate CCS deployment pathways, and substantial deployment of technologies that are currently considered less plausible.

This retrospective analysis presents a first step in the development of a better understanding of how to choose energy scenarios. Scenario choices are tightly linked to the communication with scenario users-whether researchers, stakeholders, decision makers and the wider public - who may use scenarios for a particular purpose. Thus, future research should analyse how scenario choice depends on the specific guiding question or decision to be made.

\section{Acknowledgements}

This work was conducted as part of the Energy Systems Theme of the UK Energy Research Centre Phase 2. The authors thank the anonymous reviewers for their constructive feedback. 


\section{References}

[1] Michel J-B, Shen YK, Aiden AP, Veres A, Gray MK, Team TGB, et al. Quantitative Analysis of Culture Using Millions of Digitized Books. Science. 2011;331:176-82. [2] Google NGarm Viewer. Google NGarm Viewer,. 2014.

[3] Cochran J, Mai T, Bazilian M. Meta-analysis of high penetration renewable energy scenarios. Renewable and Sustainable Energy Reviews. 2014;29:246-53.

[4] Hasan MH, Mahlia TMI, Nur H. A review on energy scenario and sustainable energy in Indonesia. Renewable and Sustainable Energy Reviews. 2012;16:2316-28.

[5] Ong HC, Mahlia TMI, Masjuki HH. A review on energy scenario and sustainable energy in Malaysia. Renewable and Sustainable Energy Reviews. 2011;15:639-47. [6] Reddy VS, Kaushik SC, Panwar NL. Review on power generation scenario of India. Renewable and Sustainable Energy Reviews. 2013;18:43-8.

[7] Miller GA. The magic number seven plus or minus two: some limits on our capacity to process information. Psychological review. 1956;63:81-97.

[8] van Vuuren DP, Riahi K, Moss R, Edmonds J, Thomson A, Nakicenovic N, et al. A proposal for a new scenario framework to support research and assessment in different climate research communities. Global Environmental Change. 2012;22:21-35.

[9] Parker AM, Srinivasan SV, Lempert RJ, Berry SH. Evaluating simulation-derived scenarios for effective decision support. Technological Forecasting and Social Change. 2014.

[10] O'Neill B, Pulver S, VanDeveer S, Garb Y. Where next with global environmental scenarios? Environmental Research Letters. 2008;3:045012.

[11] O’Neill B, Kriegler E, Riahi K, Ebi K, Hallegatte S, Carter T, et al. A new scenario framework for climate change research: the concept of shared socioeconomic pathways. Climatic Change. 2014;122:387-400.

[12] Ritchey T. Fritz Zwicky, Morphology and Policy Analysis. Stockholm: Defence Research Establishment; 1998.

[13] Morgan MG, Keith DW. Improving the way we think about projecting future energy use and emissions of carbon dioxide. Clim Change. 2008;90:189-215.

[14] Popper SW, Lempert RJ, Bankes SC. Shaping the future. Scientific American. 2005;292:66-71.

[15] Trutnevyte E, Guivarch C. Innovative Techniques for Quantitative Scenarios in Energy and Environmental Research: a Review. In: Ames DP, Quinn NWT, Rizzoli AE, 
editors. 7th International Congress on Environmental Modelling and Software Proceedings. San Diego, USA2014.

[16] Schweizer VJ, Kriegler E. Improving environmental change research with systematic techniques for qualitative scenarios. Environmental Research Letters. $2012 ; 7$.

[17] Schweizer V, O’Neill B. Systematic construction of global socioeconomic pathways using internally consistent element combinations. Clim Change. 2014;122:431-45. [18] Weimer-Jehle W. Cross-impact balances: A system-theoretical approach to crossimpact analysis. Technological Forecasting and Social Change. 2006;73:334-61. [19] von Wirth T, Wissen Hayek U, Kunze A, Neuenschwander N, Stauffacher M, Scholz RW. Identifying urban transformation dynamics: Functional use of scenario techniques to integrate knowledge from science and practice. Technological Forecasting and Social Change. 2013.

[20] Trutnevyte E. EXPANSE methodology for evaluating the economic potential of renewable energy from an energy mix perspective. Applied Energy. 2013;111:593-601. [21] Trutnevyte E, Stauffacher M, Scholz RW. Linking stakeholder visions with resource allocation scenarios and multi-criteria assessment. European Journal of Operational Research. 2012;219:762-72.

[22] Carlsen H, Dreborg K, Wikman-Svahn P. Tailor-made scenario planning for local adaptation to climate change. Mitig Adapt Strateg Glob Change. 2013;18:1239-55.

[23] Kemp-Benedict E. Telling better stories: strengthening the story in story and simulation. Environmental Research Letters. 2012;7:041004.

[24] Lempert R. Scenarios that illuminate vulnerabilities and robust responses. Clim Change. 2013;117:627-46.

[25] Lempert RJ, Popper SW, Banker SC. Shaping the Next One Hundred Years: New Methods for Quantitative, Long-term Policy Analysis. Santa Monica, CA: RAND; 2003. [26] Hulme M, Dessai S. Negotiating future climates for public policy: a critical assessment of the development of climate scenarios for the UK. Environmental Science \& Policy. 2008;11:54-70.

[27] Alcamo J. The SAS approach: Combining qualitative and quantitative knowledge in environmental scenarios. In: Alcamo J, editor. Environmental Futures: The practice of Environmental Scenario Analysis. Amsterdam: Elsevier; 2008. p. 123-50. 
[28] Fleishman LA, De Bruin WB, Morgan MG. Informed public preferences for electricity portfolios with CCS and other low-carbon technologies. Risk Analysis. 2010;30:1399-410.

[29] DECC. DECC 2050 Pathway Calculator Excel Model. Excel version 3.4.6. . DECC2014. [30] Craig PP, Gadgil A, Koomey JG. What can history teach us? A Retrospective Examination of Long-Term Energy Forecasts for the United States*. Annual Review of Energy and the Environment. 2002;27:83-118.

[31] Bradfield R, Wright G, Burt G, Cairns G, Van Der Heijden K. The origins and evolution of scenario techniques in long range business planning. Futures. 2005;37:795812.

[32] Amer M, Daim TU, Jetter A. A review of scenario planning. Futures. 2013;46:23-40.

[33] Huss WR, Honton EJ. Scenario planning-What style should you use? Long Range Planning. 1987;20:21-9.

[34] Börjeson L, Höjer M, Dreborg K-H, Ekvall T, Finnveden G. Scenario types and techniques: Towards a user's guide. Futures. 2006;38:723-39.

[35] van Notten PWF, Rotmans J, van Asselt MBA, Rothman DS. An updated scenario typology. Futures. 2003;35:423-43.

[36] Wilkinson A, Eidinow E. Evolving practices in environmental scenarios: a new scenario typology. Environmental Research Letters. 2008;3:11.

[37] Hulme M, Dessai S. Predicting, deciding, learning: can one evaluate the 'success' of national climate scenarios? Environmental Research Letters. 2008;3:045013.

[38] EEA. Looking back on looking forward: a review of evaluative scenario literature. EEA Technical Report No 3/2009. Copenhagen: European Environment Agency; 2009. [39] Schwanitz VJ. Evaluating integrated assessment models of global climate change. Environmental Modelling \& Software. 2013;50:120-31.

[40] Girod B, Wiek A, Mieg H, Hulme M. The evolution of the IPCC's emissions scenarios. Environmental Science \& Policy. 2009;12:103-18.

[41] Littlechild SC, Vaidya KG, Carey M, Soldatos PG, Rouse J, Slicer IH, et al. Energy Strategies for the UK. London: George Allen \& Unwin; 1982.

[42] Pearson P, Watson J. UK Energy Policy, 1980-2010 A history and lessons to be learned. London: IET and Parliamentary Group for Energy Studies; 2011.

[43] DECC. 60th anniversary. Digest of United Kingdom energy statistics. London: DECC; 2009. 
[44] Manning MR, Edmonds J, Emori S, Grubler A, Hibbard K, Joos F, et al.

Misrepresentation of the IPCC CO2 emission scenarios. Nature Geosci. 2010;3:376-7.

[45] Smil V. Energy at the crossroads : global perspectives and uncertainties.

Cambridge, Massachusets: The MIT Press; 2003.

[46] Hammond GP. Alternative Energy Strategies for the United Kingdom Revisited: Market Competition and Sustainability. Technological Forecasting and Social Change. 1998;59:131-51.

[47] Turner GM. A comparison of The Limits to Growth with 30 years of reality. Global Environmental Change. 2008;18:397-411.

[48] Strachan N. UK energy policy ambition and UK energy modelling-fit for purpose? Energy Policy. 2011;39:1037-40.

[49] UK Department of Energy. Energy Policy: A consultative document, Cmnd 7101. London: HMSO; 1978.

[50] Leach G, Lewis C, Romig F, van Buren A, Foley GA. A low energy strategy for the United Kingdom. London: International Institute for Environmental Development; 1979. [51] ETSU. Low energy futures : a study carried out by ETSU. Harwell: Energy Technology Support Unit; 1982.

[52] UK Department of Energy. Energy projections. London: Department of Energy 1979.

[53] Hourcade JC, Jaccard M, Bataille C, Ghersi F. Hybrid modeling: New answers to old challenges - Introduction to the special issue of The Energy Journal. Energy Journal. 2006:1-11.

[54] Schrattenholzer L. The energy supply model MESSAGE. International Institute for Applied System Analusis, Research Report. 1981;81-31.

[55] Fishbone LG, Abilock H. Markal, a linear-programming model for energy systems analysis: Technical description of the bnl version. International Journal of Energy Research. 1981;5:353-75.

[56] ETSU. An Assessment of renewable Energy for the UK. London: HMSO; 1994. [57] ETSU. Modelling gaseous emissions from the UK energy system. Harwell: Department of Trade and Industry; 1995.

[58] ETSU. An appraisal of UK energy research, development, demonstration and dissemination. London: HMSO; 1994.

[59] DTI. New and renewable energy : future prospects in the UK. London: HMSO; 1994. 
[60] DTI. Energy projections for the UK: Energy use and energy-related emissions of carbon dioxide in the UK, 1995-2020. Energy paper 65. London, UK: Department of Trade and Industry; 1995.

[61] ETSU. New and Renewable Energy: Prospects in the UK for the 21st Century: Supporting Analysis. London, UK: Energy Technology Support Unit; 1999.

[62] DTI. The Technological, Fuel and Cost Implications of Abating Gaseous Emissions from the UK Energy System. London, UK: Department of Trade and Industry; 1999. [63] DTI. Energy projections for the UK: Energy use and energy-related emissions of carbon dioxide in the UK, 2000-2020. Energy paper 68. London, UK: Department of Trade and Industry; 2000.

[64] Royal Comission on Environmental Pollution. Twenty-second report: Energy - the changing climate. London: Royal Comission on Environmental Pollution; 2000.

[65] Performance and Innovation Unit. The Energy Review. London: Performance and Innovation Unit,; 2002.

[66] National Grid. UK future energy scenarios: UK gas and electricity transmission. London: NationalGrid; 2013.

[67] Morgan G, Henrion M. Uncertainty. New York: Cambridge University Press; 1990.

[68] Scholz RW, Tietje 0. Embedded case study methods: Integrating quantitative and qualitative knowledge. Thousand Oaks: Sage; 2002.

[69] National Atmospheric Emissions Inventory. Greenhouse Gas Inventories for England, Scotland, Wales and Northern Ireland: 1990-2012. London: Ricardo-AEA; 2014.

[70] Hughes N, Strachan N. Methodological review of UK and international low carbon scenarios. Energy Policy. 2010;38:6056-65.

[71] ERP. Energy innovation milestones to 2050. London: Energy Research Partnership; 2010.

[72] McDowall W, Trutnevyte E, Tomei J, Keppo I. Reflecting on scenarios. UKERC Energy Systems Theme Working Paper UKERC/WP/ES/2014/002. London: UKERC; 2014.

[73] Goldthau A. From the State to the Market and Back: Policy Implications of Changing Energy Paradigms. Global Policy. 2012;3:198-210.

[74] Hammond GP, Pearson PJG. Challenges of the transition to a low carbon, more electric future: From here to 2050. Energy Policy. 2013;52:1-9. 
[75] Pfenninger S, Hawkes A, Keirstead J. Energy systems modeling for twenty-first century energy challenges. Renewable and Sustainable Energy Reviews. 2014;33:74-86. [76] Trutnevyte E, Barton J, O'Grady Á, Ogunkunle D, Pudjianto D, Robertson E. Linking a storyline with multiple models: A cross-scale study of the UK power system transition. Technological Forecasting and Social Change. 2014;89:26-42.

[77] McDowall W. Exploring possible transition pathways for hydrogen energy: A hybrid approach using socio-technical scenarios and energy system modelling. Futures;63:1-14.

[78] Trutnevyte E. Linking governance storylines with the D-EXPANSE model to explore the power system transition pathways. In: Ames DP, Quinn NWT, Rizzoli AE, editors. 7th International Congress on Environmental Modelling and Software Proceedings. San Diego, USA, 2014.

[79] Strachan N, Usher W. Failure to achieve stringent carbon reduction targets in a second-best policy world. Clim Change. 2012;113:121-39.

[80] DECC. Planning our electric future: a White Paper for secure, affordable and low- carbon electricity 2011.

[81] DECC. Electricity Market Reform: policy overview. London: UK Department of Energy and Climate Change; 2012.

[82] Spiegelhalter DJ, Riesch H. Don't know, can't know: embracing deeper uncertainties when analysing risks. Philosophical Transactions of the Royal Society A: Mathematical, Physical and Engineering Sciences. 2011;369:4730-50.

[83] Stirling A. Multicriteria diversity analysis: A novel heuristic framework for appraising energy portfolios. Energy Policy. 2010;38:1622-34.

[84] Kern F. The development of the CCGT and the 'dash for gas' in the UK power industry (1987-2000). London, UK: UKERC; 2012.

[85] Winskel M. When Systems are Overthrown: The 'Dash for Gas' in the British Electricity Supply Industry. Social Studies of Science. 2002;32:563-98.

[86] Trutnevyte E, Stauffacher M, Scholz RW. Supporting energy initiatives in small communities by linking visions with energy scenarios and multi-criteria assessment. Energy Policy. 2011;39:7884-95.

[87] Shell. 40 years of Shell scenarios. Hague: Shell 2012. 